\title{
The Association between Dietary Intake of Folate and Physical Activity with Psychological Dimensions of Depressive Symptoms among Students from Iran
}

\author{
Teymoor Yary \\ Department of Epidemiology, Faculty of Health, Ilam University of Medical Sciences, Ilam, Iran \\ Correspondence should be addressed to Teymoor Yary; nutcanada@gmail.com
}

Received 8 April 2013; Revised 18 September 2013; Accepted 19 September 2013

Academic Editor: Ali Khraibi

Copyright (C) 2013 Teymoor Yary. This is an open access article distributed under the Creative Commons Attribution License, which permits unrestricted use, distribution, and reproduction in any medium, provided the original work is properly cited.

\begin{abstract}
Depression in students is a major public health problem. Although several risk factors associated with depression have been identified, the cause of depression is still not clear. Several studies have demonstrated that physical activity and nutrient intake, such as increased levels of $B$ vitamins in serum, decrease symptoms of depression. The aim of this study was to investigate the association between physical activity and dietary intake of vitamins $\mathrm{B}_{6}, \mathrm{~B}_{9}$, and $\mathrm{B}_{12}$ and symptoms of depression among postgraduate students. The results of this study suggest that intake of vitamin $B_{9}$ may modulate the total score of Center for Epidemiological Studies Depression Scale (CES-D) and two subscales of the CES-D including depressive affect and interpersonal difficulties. This study also showed that moderate/high levels of physical activity were inversely and significantly associated with symptoms of depression (total scores) and three subscales of the CES-D including depressive affect, positive affect, and somatic complaints.
\end{abstract}

\section{Background}

Depression has increasingly become a public health problem in both developed [1] and developing countries [2]. Several risk factors cluster together and increase the risk of depressive disorders. Nonmodifiable, modifiable, and contextual risk factors are causes of these disorders. Advancing age, gender [3], and ethnicity [4] are examples of nonmodifiable risk factors of depression. Inflammation [5], cigarette smoking, physical inactivity, poor nutrition, and consumption of alcohol are modifiable risk factors of depression [6]. Sociodemographic variables such as education, income, health insurance, and poverty are contextual risk factors of depression. Accumulations of one or more risk factors in individuals may lead to depressive disorders and will become a public health problem when these people become unable to conduct normal activities of daily living or cause distress to other healthy people in the society.

Depressive disorders have been shown to be associated with the higher rates of mortality compared with individuals without depressive disorders [7]. These disorders have negative effects on the quality of life and decreased life expectancy, especially among the severely mentally ill [8]. It has been shown that depression has a negative impact on many diseases such as cancer [9], cardiovascular disease [2], and diabetes mellitus [10]. A significant elevation in morbidity and mortality has been shown in these diseases because of depression $[2,9,10]$.

Symptoms of depression among college students are a growing public health concern [11-13]. One out of seven students may experience depression, which usually presents as feelings of fatigue, guilt, sadness, and hopelessness. Depressed students are prone to low academic performance, withdraw from university, increased smoking, acute infection illnesses, self-injurious behavior, and suicide [14]. Depression may interfere with interpersonal relationships and performance of daily tasks, which may lead to suicidal thoughts and attempts of suicide [15].

Depression in college students may be due to several factors, including vulnerable age, demands of college life, personal issues, adaptation to a new environment, tendency toward perfectionism, and conflict between traditional and modern values $[15,16]$. There is increasing interest in the role of physical activity in the prevention and treatment 
of depression [17]. Over the last 40 years, several studies have investigated the relationship between physical activity and improvements in mental health symptoms among various populations. Many of the studies have indicated that physical activity is able to reduce the risk of several mental health conditions, especially depressive symptoms [18-20]. Numerous gaps remain in each of these individual research areas. For example, these studies have been limited by lack of data on important factors such as levels of physical activity, because although previous studies have reported that physical activity successfully decreases depression, it is not clear which levels of physical activity were related to depression [21]. Furthermore, the role of physical activity as a predictor of depression was not constant [22].

An association between depressive symptoms and polyunsaturated fatty acids or minerals has been found among university students $[2,12,23,24]$. Also, a few studies among other populations have demonstrated that dietary intake of vitamins B may decrease symptoms of depression [25-27]. However, these studies have been limited in middle age and over, and the association between dietary intake of vitamin $B$ such as vitamin $B_{9}$ has not received as much attention in special populations such as university students. Also, studies have investigated the association between physical activity and depression [28, 29]. These studies failed to control nutrients intake such as vitamins $\mathrm{B}$, which may reduce symptoms of depression, and this can confound the association between physical activity and depression. In addition, several previous studies did not investigate the relationship between the levels of physical activity with depression. The current study excluded several other confounders such as hyperthyroidism, hypertension, diabetes, cancer, or heart disease; these diseases can affect the associations between vitamins $B$ and both depression and physical activity; these confounders cannot be controlled statistically utterly. Most importantly, there is no any data (locally or universally) on the subject of vitamins B and depression and psychological dimensions of depression in university students. Taking everything into consideration, the association between vitamins B/physical activity and depressive symptoms remains unclear among university students. Therefore, the aim of this study was to investigate the association between physical activity and dietary intake of vitamins $\mathrm{B}_{6}, \mathrm{~B}_{9}$, and $\mathrm{B}_{12}$ and symptoms of depression and psychological dimensions of depression as measured by the CESD subscales (depressive affect, somatic complaints, positive affect, and interpersonal difficulties).

\section{Materials and Methods}

A cross-sectional study, designed in 2011, was performed on a convenience sample of 425 Iranian students who were studying in Malaysia, aged $32.54 \pm 6.19$ years. Based on the study design, students with serious diseases such as hyperthyroidism, hypertension, diabetes, or heart disease were excluded since such conditions may affect lifestyle (e.g., physical activity) or alter the risk factors for depression. Students who had a history of mental illness or those taking psychiatric drugs were also excluded. Consequently, 23 individuals were dropped from the study; data analyses were performed on the sample of 402 participants that remained. This study was approved by The Scientific Counselor and Director of Iranian Students Affairs in South East Asia in Malaysia, and informed consent was obtained from all participants before enrollment.

2.1. Depression Questionnaire. Symptoms of depression in our population were assessed with the Center for Epidemiologic Studies (CES-D) questionnaire [30]. Symptoms calculated with the CES-D included feelings of loneliness, appetite loss, sadness, sleep disorders, fear, and crying. This questionnaire contained twenty self-administered items, using a 4-point Likert-type scale that ranged from 0 (rarely or none of the time; less than 1 day) to 3 (most or all of the time; 5-7 days). Scores on the CES-D could range from 0 to 60 . A cut-off score of 16 or greater indicated symptoms of depression. This questionnaire has been categorized in four dimensions including depressive affect, positive affect, somatic complaints, and interpersonal difficulties [30].

2.2. Assessment of Dietary B Vitamins. Dietary intake of $B$ vitamins, including $B_{6}, B_{9}$, and $B_{12}$, was assessed with a semiquantitative food frequency questionnaire (FFQ) [31]. The FFQ has been validated in several multiethnic populations $[32,33]$ and is used to assess food consumption over the previous 12 months. Nutritionist IV software, version 3.5.2, was used to measure the amount of B vitamins consumed. Univariate analyses were performed with SPSS software to analyze the relationships between the levels of $\mathrm{B}_{6}, \mathrm{~B}_{9}$, and $\mathrm{B}_{12}$ calculated from the FFQ and the socioeconomic status and lifestyle factors of the participants.

2.3. Physical Activity Questionnaire. In the present study, physical activity was defined as leisure-time physical activity [34]. This questionnaire was used to investigate the activities the students performed during the last year, including transport to and from work during the last year. The questionnaire has a 4-point interview format or self-report items that measure physical activity. These items include 1 for almost completely inactive or low physical activity less than $2 \mathrm{~h}$ per week, 2 for low physical activity performed for $2-4 \mathrm{~h}$ per week, 3 for low physical activity intended for more than $4 \mathrm{~h}$ per week or more vigorous activity in favor of $2-4 \mathrm{~h}$ per week, and 4 for additional vigorous physical activity for over $4 \mathrm{~h}$ per week or regular heavy exercise or competitive sports many times per week. The final decision on physical activity was graded as follows: category 1 for low level of physical activity, category 2 for moderate level of physical activity, and categories 3 and 4 for high level of physical activity [34].

2.4. Statistical Analysis. Independent $t$-test was used to examine the associations between participant characteristics and symptoms of depression. To assess the association between depression and dietary intake of B vitamins, we generated a multiple linear regression model. In this model, depressive symptom was the dependent variable whereas 
vitamins $B$ intake and other variables were the independent factors.

\section{Results}

Table 1 shows the characteristics of study participants based on total depression score (CES-D) and vitamins B. Symptoms of depression were significantly associated with decreased dietary reference intake (DRI) of vitamin $\mathrm{B}_{9}$ and age. Female gender was associated with higher score of depressive symptoms and more consumption of vitamin $\mathrm{B}_{6}$ and vitamin $\mathrm{B}_{9}$ compared to males. Less education was also associated with depressive symptoms and decreased dietary intake of vitamin $\mathrm{B}_{9}$. Marital status, current smoking, former smoking, body mass index (BMI), and number of close friends were not associated with symptoms of depression or vitamins B. Monthly expenses were significantly associated with less consumption of vitamins B but not with depressive symptoms. Living in campus was not associated with depressive symptoms or the intake of vitamins B. A high level of depressive symptom was associated with low levels of physical activity, independent of vitamins B.

Table 2 presents the associations between the participants' characteristics, $D R I$ of vitamins $B_{6}, B_{9}$, and $B_{12}$ with the psychological dimensions of depression including depressive affect, somatic complaints, positive affect, and interpersonal difficulties. Less consumption of vitamin $\mathrm{B}_{9}$ was significantly associated with depressive affect and interpersonal difficulties compared with participants who consumed more vitamin $\mathrm{B}_{9}$. The psychological dimensions of depression were not related to current, past smoking, marital status, monthly expenses, and DRI of vitamins $B_{6}$ and $B_{12}$. Postgraduate students with lower education had a significant higher score of depressive affect and interpersonal difficulties. Female gender was significantly associated with depressive affect than males. Higher score of depressive affect was significantly associated with participant who had lower age. Lower BMI was also associated with higher score of depressive affect. Participant with less than five close friends had higher score of depressive affect and interpersonal difficulties compared to those with more close friends. Higher score of depressive affect, somatic complaints, and positive affect was associated with low level of physical activity. Living in campus was significantly associated with interpersonal difficulties compared to those who were living out of campus. Figures 1, 2, 3 , and 4 show the association between vitamins $B_{6}, B_{9}$, and $B_{12}$ and physical activity with psychological dimensions of depression.

Total score of the CES-D was not associated with DRI of vitamins $B_{6}$ and $B_{12}$. The score of CES-D was higher in participants who consumed fewer vitamin $B_{9}$ compared with participants who consumed more vitamin $\mathrm{B}_{9}$ (Table 3 ). This relationship total score of the CES-D and physical activity and vitamin $B_{9}$ remained even after accounting for potential confounding variables such as age and sex (Table 4).

We conducted a multiple linear regression model analysis to identify the association between physical activity and dietary intake of $\mathrm{B}$ vitamins and the psychological

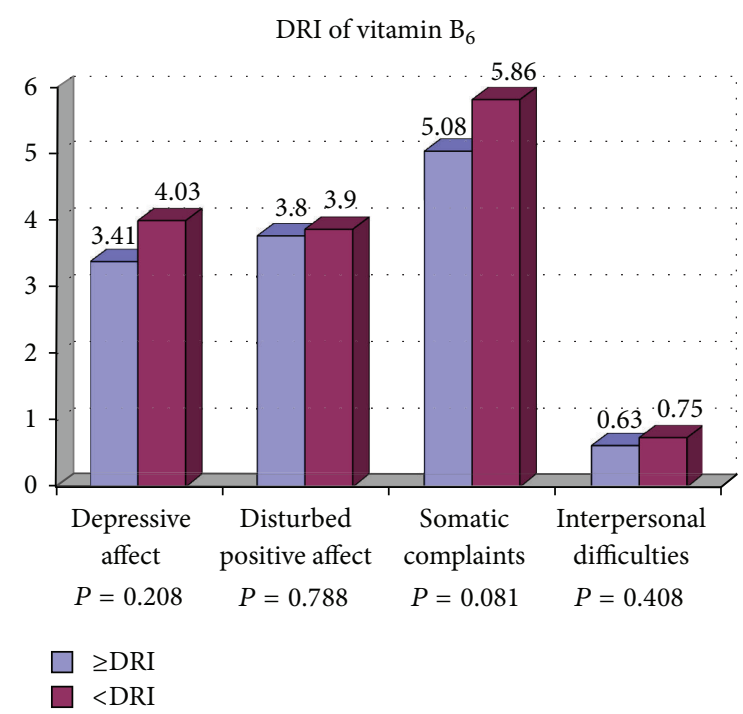

FIGURE 1: The association between vitamin $\mathrm{B}_{6}$ and psychological dimensions of depression.

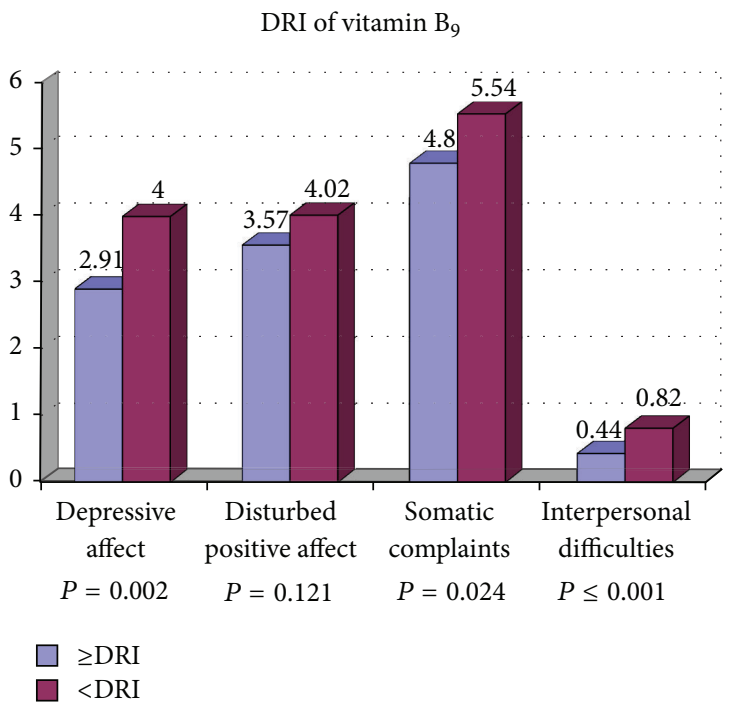

FIGURE 2: The association between vitamin $\mathrm{B}_{9}$ and psychological dimensions of depression.

dimensions of depression including depressive affect, somatic complaints, positive affect, and interpersonal difficulties. In this model, an inverse association between DRI of vitamin $\mathrm{B}_{9}$ and depressive affect, and interpersonal difficulties was found after adjusting for potential confounds, including sex, age, BMI, monthly expenses, close friends, living in campus, smoking, physical inactivity, education, marital status, and vitamins $\mathrm{B}_{6}$ and $\mathrm{B}_{12}$. This study also showed that moderate/high levels of physical activity were associated with symptoms of depression (total scores) and three subscales of the CES-D including depressive affect, positive affect, and somatic complaints (Table 5). 
TABLE 1: Characteristics of the study subjects based on overall CES-D score and vitamins B.

\begin{tabular}{|c|c|c|c|c|c|c|c|c|}
\hline Variables & $\begin{array}{c}\text { Depression score } \\
(\text { Mean } \pm \text { SD })\end{array}$ & $P$ & $\begin{array}{l}{ }^{*} \text { Vitamin } \mathrm{B}_{6} \\
(\text { Mean } \pm \mathrm{SD})\end{array}$ & $P$ & $\begin{array}{r}{ }^{* *} \text { Vitamin } \mathrm{B}_{9} \\
(\text { Mean } \pm \mathrm{SD}) \\
\end{array}$ & $P$ & $\begin{array}{r}{ }^{* *} \text { Vitamin } \mathrm{B}_{12} \\
(\text { Mean } \pm \mathrm{SD}) \\
\end{array}$ & $P$ \\
\hline Age groups & & 0.010 & & 0.309 & & 0.030 & & 0.484 \\
\hline$\leq 35(n=284)$ & $13.85 \pm 9.22$ & & $2.48 \pm 1.71$ & & $436.47 \pm 352.53$ & & $3.62 \pm 2.96$ & \\
\hline$>35(n=118)$ & $11.59 \pm 7.37$ & & $2.66 \pm 1.25$ & & $526.52 \pm 432.16$ & & $3.90 \pm 5.18$ & \\
\hline Gender & & 0.031 & & 0.008 & & 0.004 & & 0.178 \\
\hline Female $(n=173)$ & $14.27 \pm 9.46$ & & $2.79 \pm 1.91$ & & $529.98 \pm 478.82$ & & $4.00 \pm 4.70$ & \\
\hline Male $(n=229)$ & $12.37 \pm 8.13$ & & $2.34 \pm 1.32$ & & $412.23 \pm 272.25$ & & $3.48 \pm 2.81$ & \\
\hline Education & & 0.001 & & 0.068 & & 0.031 & & 0.295 \\
\hline$<20$ y $(n=199)$ & $14.60 \pm 9.23$ & & $2.38 \pm 1.58$ & & $421.66 \pm 344.75$ & & $3.50 \pm 2.32$ & \\
\hline$\geq 20 y(n=203)$ & $11.80 \pm 8.08$ & & $2.68 \pm 1.64$ & & $503.33 \pm 407.21$ & & $3.89 \pm 4.74$ & \\
\hline Marital status & & 0.289 & & 0.323 & & 0.111 & & 0.855 \\
\hline Married $(n=208)$ & $12.74 \pm 7.82$ & & $2.61 \pm 1.38$ & & $492.04 \pm 358.89$ & & $3.73 \pm 4.03$ & \\
\hline Single $(n=194)$ & $13.66 \pm 9.68$ & & $2.45 \pm 1.83$ & & $431.66 \pm 398.64$ & & $3.66 \pm 3.43$ & \\
\hline Current smoking & & 0.700 & & 0.875 & & 0.711 & & 0.235 \\
\hline Yes $(n=36)$ & $13.13 \pm 8.82$ & & $2.54 \pm 1.64$ & & $465.10 \pm 388.69$ & & $3.63 \pm 3.53$ & \\
\hline No $(n=366)$ & $13.72 \pm 8.28$ & & $2.49 \pm 1.36$ & & $440.51 \pm 269.16$ & & $4.41 \pm 5.51$ & \\
\hline Former smoking & & 0.338 & & 0.356 & & 0.327 & & 0.860 \\
\hline Yes $(n=16)$ & $13.27 \pm 8.79$ & & $2.55 \pm 1.64$ & & $466.68 \pm 385.22$ & & $3.71 \pm 3.80$ & \\
\hline No $(n=386)$ & $11.13 \pm 8.26$ & & $2.17 \pm 0.95$ & & $371.73 \pm 168.94$ & & $3.54 \pm 2.17$ & \\
\hline BMI & & 0.084 & & 0.347 & & 0.919 & & 0.635 \\
\hline$\leq 25(n=262)$ & $13.74 \pm 8.96$ & & $2.48 \pm 1.67$ & & $464.31 \pm 424.30$ & & $3.77 \pm 4.42$ & \\
\hline$>25(n=140)$ & $12.15 \pm 8.34$ & & $2.64 \pm 1.45$ & & $460.27 \pm 277.56$ & & $3.58 \pm 1.95$ & \\
\hline Monthly expenses (\$) & & 0.862 & & 0.014 & & 0.009 & & 0.020 \\
\hline$<800(n=199)$ & $13.10 \pm 8.85$ & & $2.33 \pm 1.65$ & & $411.68 \pm 349.97$ & & $3.25 \pm 2.28$ & \\
\hline$\geq 800(n=210)$ & $13.26 \pm 8.71$ & & $2.72 \pm 1.56$ & & $509.73 \pm 399.41$ & & $4.12 \pm 4.69$ & \\
\hline Close friends & & 0.077 & & 0.117 & & 0.122 & & 0.263 \\
\hline$<5(n=220)$ & $13.89 \pm 9.03$ & & $2.42 \pm 1.67$ & & $436.25 \pm 370.16$ & & $3.51 \pm 3.07$ & \\
\hline$\geq 5(n=182)$ & $12.34 \pm 8.38$ & & $2.67 \pm 1.54$ & & $495.12 \pm 388.69$ & & $3.93 \pm 4.42$ & \\
\hline Physical activity & & $\leq 0.001$ & & 0.485 & & 0.969 & & 0.206 \\
\hline$\geq$ Moderate $(n=274)$ & $11.89 \pm 8.06$ & & $2.57 \pm 1.71$ & & $462.40 \pm 366.16$ & & $3.49 \pm 2.38$ & \\
\hline Low $(n=128)$ & $15.95 \pm 9.58$ & & $2.45 \pm 1.39$ & & $463.97 \pm 407.56$ & & $4.15 \pm 5.64$ & \\
\hline Living in campus & & 0.155 & & 0.920 & & 0.467 & & 0.070 \\
\hline Yes $(n=170)$ & $13.91 \pm 9.58$ & & $2.52 \pm 1.62$ & & $478.99 \pm 436.08$ & & $3.38 \pm 2.05$ & \\
\hline No $(n=232)$ & $12.65 \pm 8.10$ & & $2.54 \pm 1.61$ & & $451.11 \pm 332.14$ & & $4.14 \pm 5.22$ & \\
\hline
\end{tabular}

\section{Discussion}

The present cross-sectional study determined that inverse relationships existed between intake of vitamin $\mathrm{B}_{9}$ and the total score of CES-D and two subscales of the CES-Dscore including depressive affect and interpersonal difficulties among university students. This study also showed that moderate/high levels of physical activity were inversely and significantly associated with symptoms of depression (total scores) and three subscales of the CES-D including depressive affect, positive affect, and somatic complaints. The associations persisted even after adjusting for sex, age, BMI, monthly expenses, close friends, living in campus, smoking (current and former), education, marital status, and vitamins $\mathrm{B}_{6}$ and $\mathrm{B}_{12}$.

To the best our knowledge this is the first study to show an association between physical activity and vitamin $B_{9}$ intake and the psychological dimensions of depression among Iranian university students. Our results and methodology used in this cross-sectional study is novel and unique because no 
TABLE 2: The association between vitamins B and characteristics of the subjects and psychological dimensions of depression.

\begin{tabular}{|c|c|c|c|c|c|c|c|c|}
\hline Variables & $\begin{array}{c}\text { Depressive affect } \\
(\text { Mean } \pm \text { SD })\end{array}$ & $P$ & $\begin{array}{c}\text { Disturbed positive } \\
\text { affect } \\
(\text { Mean } \pm \mathrm{SD}) \\
\end{array}$ & $P$ & $\begin{array}{c}\text { Somatic } \\
\text { complaints } \\
(\text { Mean } \pm \mathrm{SD})\end{array}$ & $P$ & $\begin{array}{c}\text { Interpersonal } \\
\text { difficulties } \\
(\text { Mean } \pm \text { SD) } \\
\end{array}$ & $P$ \\
\hline DRI of vitamin $B_{6}$ & & 0.208 & & 0.788 & & 0.081 & & 0.408 \\
\hline$\geq \mathrm{DRI}(n=338)$ & $3.41 \pm 3.56$ & & $3.80 \pm 2.89$ & & $5.08 \pm 3.14$ & & $0.63 \pm 1.05$ & \\
\hline$<\mathrm{DRI}(n=64)$ & $4.03 \pm 3.85$ & & $3.90 \pm 3.09$ & & $5.86 \pm 3.73$ & & $0.75 \pm 1.10$ & \\
\hline DRI of vitamin $B_{9}$ & & 0.002 & & 0.121 & & 0.024 & & $\leq 0.001$ \\
\hline$\geq \mathrm{DRI}(n=183)$ & $2.91 \pm 2.99$ & & $3.57 \pm 2.58$ & & $4.80 \pm 2.86$ & & $0.44 \pm 0.89$ & \\
\hline$<\mathrm{DRI}(n=219)$ & $4.00 \pm 3.99$ & & $4.02 \pm 2.97$ & & $5.54 \pm 3.51$ & & $0.82 \pm 1.16$ & \\
\hline DRI of vitamin $B_{12}$ & & 0.300 & & 0.230 & & 0.184 & & 0.968 \\
\hline$\geq \mathrm{DRI}(n=264)$ & $3.37 \pm 3.67$ & & $3.69 \pm 2.90$ & & $5.05 \pm 3.15$ & & $0.65 \pm 1.13$ & \\
\hline$<\mathrm{DRI}(n=138)$ & $3.77 \pm 3.47$ & & $4.06 \pm 2.97$ & & $5.51 \pm 3.42$ & & $0.65 \pm 0.93$ & \\
\hline Age groups & & 0.001 & & 0.178 & & 0.065 & & 0.375 \\
\hline$\leq 35(n=284)$ & $3.83 \pm 3.84$ & & $3.94 \pm 2.96$ & & $5.38 \pm 3.41$ & & $0.68 \pm 1.11$ & \\
\hline$>35(n=118)$ & $2.72 \pm 2.83$ & & $3.52 \pm 2.82$ & & $4.78 \pm 2.80$ & & $0.58 \pm 0.95$ & \\
\hline Gender & & $\leq 0.001$ & & 0.092 & & 0.996 & & 0.311 \\
\hline Male $(n=229)$ & $2.95 \pm 3.21$ & & $3.60 \pm 2.82$ & & $5.21 \pm 3.16$ & & $0.60 \pm 1.02$ & \\
\hline Female $(n=173)$ & $4.25 \pm 3.26$ & & $4.10 \pm 3.04$ & & $5.21 \pm 3.38$ & & $0.71 \pm 1.11$ & \\
\hline Education & & $\leq 0.001$ & & 0.053 & & 0.051 & & 0.007 \\
\hline$<20$ y $(n=199)$ & $4.18 \pm 3.76$ & & $4.10 \pm 2.88$ & & $5.53 \pm 3.94$ & & $0.79 \pm 1.18$ & \\
\hline$\geq 20 y(n=203)$ & $2.86 \pm 3.34$ & & $3.54 \pm 2.95$ & & $4.90 \pm 3.08$ & & $0.51 \pm 0.91$ & \\
\hline Marital status & & 0.051 & & 0.651 & & 0.553 & & 0.134 \\
\hline Married $(n=208)$ & $3.17 \pm 3.17$ & & $3.88 \pm 2.85$ & & $5.12 \pm 2.96$ & & $0.57 \pm 0.94$ & \\
\hline Single $(n=194)$ & $3.88 \pm 4.00$ & & $3.74 \pm 3.00$ & & $5.31 \pm 3.54$ & & $0.73 \pm 1.17$ & \\
\hline Current smoking & & 0.676 & & 0.607 & & 0.980 & & 0.789 \\
\hline Yes $(n=36)$ & $3.75 \pm 2.72$ & & $4.06 \pm 3.10$ & & $5.22 \pm 3.23$ & & $0.69 \pm 1.14$ & \\
\hline No $(n=366)$ & $3.49 \pm 3.69$ & & $3.79 \pm 2.91$ & & $5.21 \pm 3.26$ & & $0.64 \pm 1.05$ & \\
\hline Former smoking & & 0.225 & & 0.255 & & 0.979 & & 0.567 \\
\hline Yes $(n=16)$ & $2.44 \pm 3.24$ & & $3.00 \pm 3.31$ & & $5.19 \pm 2.37$ & & $0.50 \pm 1.10$ & \\
\hline No $(n=386)$ & $3.55 \pm 3.62$ & & $3.85 \pm 2.91$ & & $5.21 \pm 3.28$ & & $0.66 \pm 1.06$ & \\
\hline BMI & & 0.006 & & 0.469 & & 0.455 & & 0.437 \\
\hline$\leq 25(n=262)$ & $3.87 \pm 3.82$ & & $3.89 \pm 2.97$ & & $5.30 \pm 3.40$ & & $0.68 \pm 1.07$ & \\
\hline$>25(n=140)$ & $2.84 \pm 3.30$ & & $3.67 \pm 3.02$ & & $5.05 \pm 2.95$ & & $0.59 \pm 1.04$ & \\
\hline Monthly expenses & & 0.780 & & 0.211 & & 0.445 & & 0.196 \\
\hline$<800(n=199)$ & $3.56 \pm 3.62$ & & $3.63 \pm 2.75$ & & $5.34 \pm 3.31$ & & $0.58 \pm 0.97$ & \\
\hline$\geq 800(n=210)$ & $3.46 \pm 3.60$ & & $3.99 \pm 3.07$ & & $5.10 \pm 3.19$ & & $0.71 \pm 1.14$ & \\
\hline Close friends & & 0.020 & & 0.187 & & 0.853 & & 0.009 \\
\hline$<5(n=220)$ & $3.89 \pm 3.81$ & & $4.00 \pm 3.03$ & & $5.24 \pm 3.31$ & & $0.77 \pm 1.15$ & \\
\hline$\geq 5(n=182)$ & $3.05 \pm 3.29$ & & $3.60 \pm 2.78$ & & $5.18 \pm 3.19$ & & $0.50 \pm 0.93$ & \\
\hline Physical activity & & $\leq 0.001$ & & 0.006 & & $<0.001$ & & 0.056 \\
\hline$\geq$ Moderate $(n=274)$ & $2.97 \pm 3.31$ & & $3.54 \pm 2.81$ & & $4.79 \pm 3.06$ & & $0.58 \pm 1.01$ & \\
\hline Low $(n=128)$ & $4.66 \pm 3.95$ & & $4.40 \pm 3.08$ & & $6.10 \pm 3.47$ & & $0.80 \pm 1.15$ & \\
\hline Living in campus & & 0.340 & & 0.964 & & 0.052 & & 0.026 \\
\hline Yes $(n=170)$ & $3.72 \pm 4.05$ & & $3.82 \pm 2.74$ & & $5.58 \pm 3.49$ & & $0.79 \pm 1.24$ & \\
\hline No $(n=232)$ & $3.36 \pm 4.24$ & & $3.81 \pm 3.05$ & & $4.94 \pm 3.04$ & & $0.54 \pm 0.89$ & \\
\hline
\end{tabular}

DRI for vitamin $\mathrm{B}_{6}: 19-50 \mathrm{y}=1.3 \mathrm{mg} / \mathrm{d},>50 \mathrm{y}=1.7 \mathrm{mg} / \mathrm{d}$; DRI for vitamin $\mathrm{B}_{9}: 400 \mu \mathrm{g} / \mathrm{d}$; DRI for vitamin $\mathrm{B}_{12}: 2.4 \mu / \mathrm{d}$ (DRI 1998). 
TABLE 3: Association between vitamins B and overall CES-D score.

\begin{tabular}{|c|c|c|c|c|c|c|c|c|c|}
\hline \multirow{2}{*}{ Variables } & \multicolumn{2}{|c|}{ DRI of vitamin $B_{6}$} & \multirow{2}{*}{$P$} & \multicolumn{2}{|c|}{ DRI of vitamin $B_{9}$} & \multirow{2}{*}{$P$} & \multicolumn{2}{|c|}{ DRI of vitamin $B_{12}$} & \multirow{2}{*}{$P$} \\
\hline & $\begin{array}{c}\geq \mathrm{DRI} \\
(N=338)\end{array}$ & $\begin{array}{c}<\mathrm{DRI} \\
(N=64)\end{array}$ & & $\begin{array}{c}\geq \mathrm{DRI} \\
(N=183)\end{array}$ & $\begin{array}{c}<\mathrm{DRI} \\
(N=219)\end{array}$ & & $\begin{array}{c}\geq \mathrm{DRI} \\
(N=264)\end{array}$ & $\begin{array}{c}<\text { DRI } \\
(N=138)\end{array}$ & \\
\hline $\begin{array}{l}\text { The score of } \\
\text { CES-D } \\
(\text { Mean } \pm \text { SD) }\end{array}$ & $12.93 \pm 8.56$ & $14.55 \pm 9.76$ & 0.175 & $11.73 \pm 7.24$ & $14.40 \pm 9.72$ & 0.002 & $12.77 \pm 8.75$ & $13.96 \pm 8.77$ & 0.186 \\
\hline
\end{tabular}

TABLE 4: Association between vitamins B intake and physical activity and depressive symptoms in a regression model.

\begin{tabular}{lccc}
\hline Variables & $\beta$ & $t$ & $P$ \\
\hline DRI of vitamin $\mathrm{B}_{9}(\geq$ DRI versus $<$ DRI) & -0.14 & 2.48 & 0.014 \\
Physical activity $(\geq$ moderate versus low) & -0.21 & 4.34 & $\leq 0.001$ \\
\hline
\end{tabular}

Adjusted for sex (male, female), age (continuous), BMI (continuous), monthly expenses (continuous), close friends (continuous), living in campus (yes versus no), smoking (yes versus no), education (continuous), marital status (yes versus no), and vitamins $\mathrm{B}_{6}$ (continuous) and $\mathrm{B}_{12}$ (continuous).

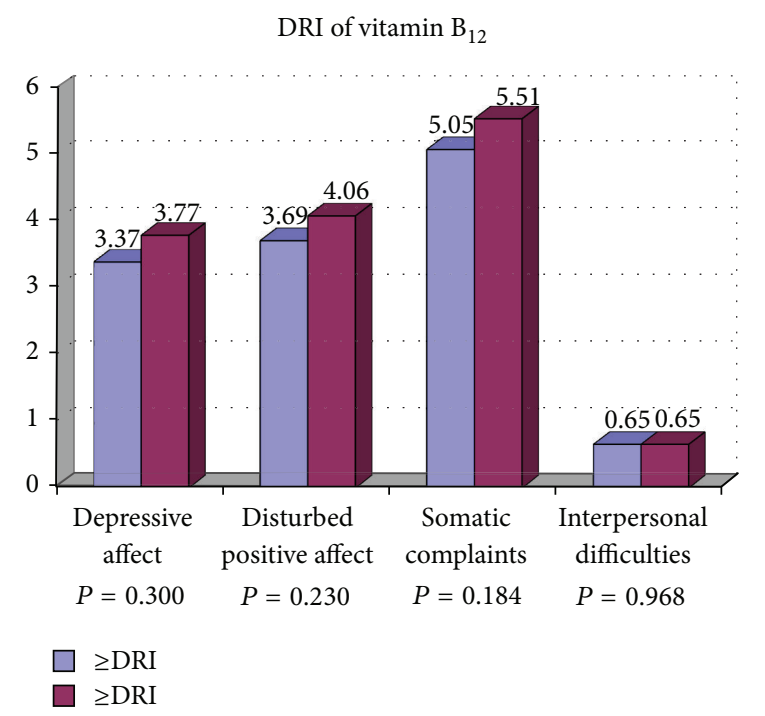

FIgURE 3: The association between vitamin $\mathrm{B}_{12}$ and psychological dimensions of depression.

study has investigated the association between depression/the psychological dimensions of depression and vitamins B and the levels of physical activity among university students.

An inverse association between depressive symptoms and vitamin $\mathrm{B}_{9}$ among our population can be supported by previous cross-sectional studies. A cross-sectional study documented that low intake of vitamin $B_{9}$ was inversely associated with depression among currently smoking men and men with low anxiety levels [35]. A second cross-sectional study also showed a significant association between lower depressive symptoms and higher dietary intakes of vitamin $B_{9}$ in middle-aged ( $42-60 \mathrm{y}$ ) men; the association was not found for other vitamins such as vitamins $B_{6}$ and $B_{12}$ [36]. A third cross-sectional study found an inverse association between vitamin $\mathrm{B}_{9}$ intake and prevalence of depression among men as well as an inverse association between depression and

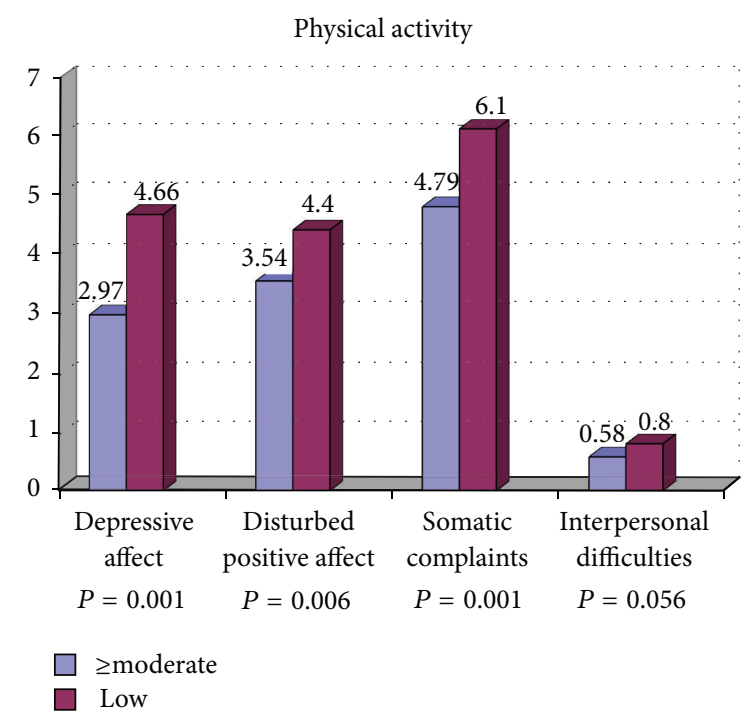

FIGURE 4: The association between physical activity and psychological dimensions of depression.

vitamin $\mathrm{B}_{12}$ among women; mean age was 41 and 34 years for men and women, respectively [37]. Conversely, the fourth cross-sectional study in men, aged 70-90 years, does not detected a relationship between symptoms of depression and vitamins $B_{6}, B_{9}$, and $B_{12}$ [38]. Despite the results described above, it has been documented that vitamins $B_{6}$ and $B_{12}$ are involved in the synthesis of monoamines neurotransmitters in the central nervous system, such as dopamine, serotonin, norepinephrine, and epinephrine [39, 40].

The mechanism underlying the relationship between depression and vitamin $\mathrm{B}_{9}$ is unknown, but it can partly explain the role of vitamin $B_{9}$ in the regulation of homocysteine. It was found that hyperhomocysteinemia is associated with depressive disorders [41]. For instance, research showed that more than $50 \%$ of depressed patients have hyperhomocysteinemia [42]. Homocysteine can increase oxidative stress, apoptosis, and DNA strand breakage; it is also directly toxic to neurons and blood vessels [43], and the vascular system of depressed patients may be destroyed by homocysteine. Three vitamins including $\mathrm{B}_{6}, \mathrm{~B}_{9}$, and $\mathrm{B}_{12}$ are involved in the regulation of homocysteine $[43,44]$. However, it has been indicated that hyperhomocysteinemia was more common in patients with vitamin $\mathrm{B}_{9}$ deficiencies [45]. One possible explanation involves dysfunction of metabolic pathways that require $\mathrm{S}$-adenosylmethionine (SAM), which serves as a methyl donor in numerous biochemical processes including 
TABLE 5: The association between DRI of vitamin $\mathrm{B}_{9}$ and physical activity and psychological dimensions of depression in a regression model.

\begin{tabular}{lccccccccccccc}
\hline \multirow{2}{*}{ Variables } & \multicolumn{3}{c}{ Depressive affect } & \multicolumn{3}{c}{ Disturbed positive affect } & \multicolumn{3}{c}{ Somatic complaints } & \multicolumn{3}{c}{ Interpersonal difficulties } \\
& $\beta$ & $t$ & $P$ & $\beta$ & $t$ & $P$ & $\beta$ & $t$ & $P$ & $\beta$ & $t$ & $P$ \\
\hline Vitamin $\mathrm{B}_{9}$ & -0.13 & 2.48 & 0.014 & -0.07 & 1.18 & 0.239 & -0.08 & 1.40 & 0.163 & -0.21 & 3.83 & $\leq 0.001$ \\
Physical activity & -0.22 & 4.51 & $\leq 0.001$ & -0.12 & 2.43 & 0.016 & -0.19 & 3.74 & $\leq 0.001$ & -0.10 & 1.95 & 0.052 \\
\hline
\end{tabular}

Adjusted for sex (male, female), age (continuous), BMI (continuous), monthly expenses (continuous), close friends (continuous), living in campus (yes versus no), smoking (yes versus no), education (continuous), marital status (yes versus no), vitamin $\mathrm{B}_{6}$ (continuous), vitamin $\mathrm{B}_{12}$ (continuous), vitamin $\mathrm{B}_{9}$ ( $\geq \mathrm{DRI}$ versus $<$ DRI), and physical activity ( $\geq$ moderate versus low).

those important for neurological function. Under homeostatic conditions, SAM is formed from methionine but is subsequently metabolized to homocysteine after serving as a methyl donor. Vitamin $\mathrm{B}_{9}$ is required to donate onecarbon groups to homocysteine to recycle it to methionine for continued SAM formation. Deficiencies in vitamin $B_{9}$ lead to accumulation of homocysteine, decreased SAM, and therefore impairment of neurological function [46-49].

Vitamin $\mathrm{B}_{9}$ deficiency may increase symptoms of depression by impairing the synthesis of tetrahydrobiopterin (BH4). BH4 is a compulsory cofactor for the three aromatic amino acids (tryptophan, phenylalanine, and tyrosine) hydroxylase enzymes. The three aromatic amino acids produce several neurotransmitters including serotonin (5hydroxytryptamine, 5-TH), dopamine, melatonin, norepinephrine, and epinephrine [50]. Deregulation of this reaction may lead to abnormalities in the synthesis of mentioned neurotransmitters $[51,52]$, as well as depression [50].

The present study found an inverse association between depressive symptoms and moderate/high levels of physical activity among Iranian university students. Previous crossseveral studies have shown that less depressive symptoms are associated with physically active individuals $[28,29]$. The dose-response correlation between differing levels of physical activity and depression symptoms is not very clear. In only a few studies, individuals were categorized according to their level of physical activity into 2 or more groups to investigate a dose gradient relationship with depressive symptoms. A cross-sectional study conducted on adolescents found that total amount of physical activity was associated with symptoms of depression; however, moderate and vigorous physical activity was not independently related to depressive symptoms [28]. In contrast, a cross-sectional study concluded that high levels of physical activity were associated with less depression as compared to low level of physical activity [53].

There are several proposed mechanisms for the relationship between physical activity and depression symptoms. The effects of physical activity on depression mechanisms can be explained with both psychological and physiological/biochemical theories. It is to be expected that a combination of mechanisms influences the link between physical activity and depression [54]. Several factors related to depressive symptoms such as the sense of enjoyment, fulfillment, and social interactions can be provided by physical activities during leisure time [55]. One of the most frequently proposed mechanisms for the antidepressant effect of physical activity is cognitive-behavioral hypothesis [56]. The hypothesis suggests that negative feelings that may cause depression and activity releases may block these conditions. Physical activity seems to increase skill mastery, self-efficacy, feelings of success, and locus of control, and a lack of these factors is associated with depression symptoms [54]. Also, the time out/distraction hypothesis suggests that physical activity helps individuals overcome their daily worries and thus reduces depression symptoms $[54,56]$.

The effect of physical activity as an antidepressant can be further explained by the amine hypothesis. Individuals with depression have lower levels of monoamine neurotransmitters, including serotonin [57], dopamine, and norepinephrine [58]. Exercise can increase the level of these neurotransmitters [54]; this hypothesis is supported by antidepressant drugs such as tricyclic monoamine oxidase inhibitors and electroconvulsive therapy, all of which raise the level of amine transmission [56]. Furthermore, according to the endorphin hypothesis, exercise influences depression with an increased discharge of $\beta$-endorphins. Endorphins have a positive effect on mood and improve sense of happiness [59].

Physical activity can also modify several risk factors related to depressive symptoms. Many biological risk factors such as glucose intolerance, inflammation, and vascular dysfunction can be improved by physical activity; these factors have shown to trigger possibly important mechanisms leading to depression [60].

Our study found that women have higher levels of depressive symptoms as well as high consumption of vitamins $\mathrm{B}_{6}$ and $\mathrm{B}_{9}$ compared to men. A number of studies have shown that women have higher prevalence of depression versus men $[56,61]$; however, the mechanism remains unclear. Researcher are trying to explain these differences through biological, psychological, genetic, and social factors $[62,63]$. Higher levels of two psychological factors including interpersonal orientation and rumination among women were shown to be associated with the higher levels of depression [63]. Also, it has been suggested that higher rates of sexual harassment, poverty, chronic strain, and child abuse among females compared to men may cause of higher level of depressive symptoms [63]. In the matter of biological factors, the serotoninergic activity in the brain can be changed with female gonadal hormones, although the mechanism is not clear, but it is possible that gonadal hormones alter the regulation of the level of monoamines such as serotonin [64].

\section{Limitation of Study}

We controlled for several important variables linked with depression that may confound interpretation of the data, 
including sex, age, BMI, monthly expenses, close friends, living in campus, smoking habit, education, physical activity, and marital status. However, this study was a cross-sectional design, and therefore causality of dietary intake of vitamin $\mathrm{B}_{9}$ or physical activity and depressive symptoms cannot be determined.

\section{Conclusion}

The results of this study suggest that physical activity and intake of vitamin $B_{9}$ may modulate the total score of CES$\mathrm{D}$ and psychological dimensions of depressive symptoms in university students.

\section{Conflict of Interests}

The authors declare that they have no conflict interests.

\section{Acknowledgments}

The author would like to acknowledge all Iranian students in Malaysia, especially the students who were participants in this study. He also wishes to express his sincerest appreciation to Dr. Siavash Yari for guiding him and for encouraging and supporting him in this study.

\section{References}

[1] A. Yeung, "Effects of qigong on depression: a systemic review," Evidence-Based Complementary and Alternative Medicine, vol. 2013, Article ID 134737, 8 pages, 2013.

[2] T. Yary, K. Soleimannejad, F. Abd Rahim et al., "Contribution of diet and major depression to incidence of acute myocardial infarction (AMI)," Lipids in Health and Disease, vol. 9, article 133, 2010.

[3] E. Stordal, M. Bjartveit Krüger, N. H. Dahl, O. Krüger, A. Mykletun, and A. A. Dahl, "Depression in relation to age and gender in the general population: the Nord-Trøndelag health study (HUNT)," Acta Psychiatrica Scandinavica, vol. 104, no. 3, pp. 210-216, 2001.

[4] S. A. Riolo, T. A. Nguyen, J. F. Greden, and C. A. King, "Prevalence of depression by race/ethnicity: findings from the national health and nutrition examination survey III," The American Journal of Public Health, vol. 95, no. 6, pp. 998-1000, 2005.

[5] M. J. Stuart and B. T. Baune, "Depression and type 2 diabetes: inflammatory mechanisms of a psychoneuroendocrine comorbidity," Neuroscience and Biobehavioral Reviews, vol. 36, no. 1, pp. 658-676, 2012.

[6] J. Parks, D. Svendsen, P. Singer, M. E. Foti, and B. Mauer, Morbidity and Mortality in People with Serious Mental Illness, National Association of State Mental Health Program Directors Medical Directors Council, Alexandria, VA, USA, 2006.

[7] F. Angst, H. H. Stassen, P. J. Clayton, and J. Angst, "Mortality of patients with mood disorders: follow-up over 34-38 years," Journal of Affective Disorders, vol. 68, no. 2-3, pp. 167-181, 2002.

[8] K. Mystakidou, E. Tsilika, E. Parpa, E. Katsouda, A. Galanos, and L. Vlahos, "Assessment of anxiety and depression in advanced cancer patients and their relationship with quality of life," Quality of Life Research, vol. 14, no. 8, pp. 1825-1833, 2005.
[9] J. Giese-Davis, K. Collie, K. M. Rancourt, E. Neri, H. C. Kraemer, and D. Spiegel, "Decrease in depression symptoms is associated with longer survival in patients with metastatic breast cancer: a secondary analysis," Journal of Clinical Oncology, vol. 29, no. 4, pp. 413-420, 2011.

[10] A. Pan, M. Lucas, Q. Sun et al., "Increased mortality risk in women with depression and diabetes mellitus," Archives of General Psychiatry, vol. 68, no. 1, pp. 42-50, 2011.

[11] C. B. Young, D. Z. Fang, and S. Zisook, "Depression in AsianAmerican and Caucasian undergraduate students," Journal of Affective Disorders, vol. 125, no. 1-3, pp. 379-382, 2010.

[12] T. Yary and S. Aazami, "Dietary intake of zinc was inversely associated with depression," Biological Trace Element Research, vol. 145, no. 3, pp. 286-290, 2012.

[13] S. R. Furr, J. S. Westefeld, G. N. McConnell, and J. M. Jenkins, "Suicide and depression among college students: a decade later," Professional Psychology, vol. 32, no. 1, pp. 97-100, 2001.

[14] J. L. Buchanan, "Prevention of depression in the college student population: a review of the literature," Archives of Psychiatric Nursing, vol. 26, no. 1, pp. 21-42, 2012.

[15] J. D. Hovey, S. E. Kim, and L. D. Seligman, "The influences of cultural values, ethnic identity, and language use on the mental health of Korean American college students," Journal of Psychology, vol. 140, no. 5, pp. 499-511, 2006.

[16] I. Ahmed, H. Banu, R. Al-Fageer, and R. Al-Suwaidi, "Cognitive emotions: depression and anxiety in medical students and staff," Journal of Critical Care, vol. 24, no. 3, pp. el-e7, 2009.

[17] J. Sallis and N. Owen, Physical Activity and Behavioral Medicine, SAGE Publications, 1998.

[18] F. Dimeo, M. Bauer, I. Varahram, G. Proest, and U. Halter, "Benefits from aerobic exercise in patients with major depression: a pilot study," The British Journal of Sports Medicine, vol. 35, no. 2, pp. 114-117, 2001.

[19] A. L. Dunn, M. H. Trivedi, and H. A. O'Neal, "Physical activity dose-response effects on outcomes of depression and anxiety," Medicine and Science in Sports and Exercise, vol. 33, no. 6, pp. S587-S597, 2001.

[20] G. Wyshak, "Women's college physical activity and self-reports of physician-diagnosed depression and of current symptoms of psychiatric distress," Journal of Women's Health and GenderBased Medicine, vol. 10, no. 4, pp. 363-370, 2001.

[21] R. D. Goodwin, "Association between physical activity and mental disorders among adults in the United States," Preventive Medicine, vol. 36, no. 6, pp. 698-703, 2003.

[22] M. Teychenne, K. Ball, and J. Salmon, "Physical activity and likelihood of depression in adults: a review," Preventive Medicine, vol. 46, no. 5, pp. 397-411, 2008.

[23] T. Yary and S. Aazami, "The association between polyunsaturated fatty acids and depression among Iranian postgraduate students in Malaysia," Lipids in Health and Disease, vol. 10, article 151, 2011.

[24] T. Yary and S. Aazami, "The association between polyunsaturated fatty acids and depression among Iranian postgraduate students in Malaysia," Lipids in Health and Disease, vol. 10, article 151, 2011.

[25] G. Astorg, A. Couthouis, and G. P. deCourcy, "Association of folate intake with the occurrence of depressive episodes in middle-aged French men and women. British Journal of Nutrition," British Journal of Nutrition, vol. 100, no. 1, p. 7, 2008.

[26] A. Sánchez-Villegas, J. Doreste, J. Schlatter, J. Pla, M. BesRastrollo, and M. A. Martínez-González, "Association between 
folate, vitamin B6 and vitamin B12 intake and depression in the SUN cohort study," Journal of Human Nutrition and Dietetics, vol. 22, no. 2, pp. 122-133, 2009.

[27] T. Tolmunen, S. Voutilainen, J. Hintikka et al., "Dietary folate and the risk of depression in finnish middle-aged men," The Journal of Nutrition, vol. 133, no. 10, pp. 3233-3236, 2003.

[28] N. J. Wiles, A. M. Haase, D. A. Lawlor, A. Ness, and G. Lewis, "Physical activity and depression in adolescents: crosssectional findings from the ALSPAC cohort," Social Psychiatry and Psychiatric Epidemiology, vol. 47, pp. 1023-1033, 2012.

[29] L. J. Chen, C. Stevinson, P. W. Ku, Y. K. Chang, and D. C. Chu, "Relationships of leisure-time and non-leisure-time physical activity with depressive symptoms: a population-based study of Taiwanese older adults," International Journal of Behavioral Nutrition and Physical Activity, vol. 9, article 28, 2012.

[30] L. S. Radloff, “The CES-D scale: a self-report depression scale for research in the general population," Applied Psychological Measurement, vol. 1, p. 385, 1977.

[31] W. C. Willett, L. Sampson, M. J. Stampfer et al., "Reproducibility and validity of a semiquantitative food frequency questionnaire," The American Journal of Epidemiology, vol. 122, no. 1, pp. 51-65, 1985.

[32] S. M. Kimiagar, M. Ghaffarpour, A. Houshiar-Rad, H. Hormozdyari, and L. Zellipour, "Food consumption pattern in the Islamic Republic of Iran and its relation to coronary heart disease," Eastern Mediterranean Health Journal, vol. 4, no. 3, pp. 539-547, 1998.

[33] I. Romieu, S. Parra, J. F. Hernández, H. Madrigal, W. Willett, and M. Hernández, "Questionnaire assessment of antioxidants and retinol intakes in Mexican women," Archives of Medical Research, vol. 30, no. 3, pp. 224-239, 1999.

[34] S. S. Mikkelsen, J. S. Tolstrup, E. M. Flachs, E. L. Mortensen, P. Schnohr, and T. Flensborg-Madsen, "A cohort study of leisure time physical activity and depression," Preventive Medicine, vol. 51, no. 6, pp. 471-475, 2010.

[35] A. Sánchez-Villegas, J. Doreste, J. Schlatter, J. Pla, M. BesRastrollo, and M. A. Martínez-González, "Association between folate, vitamin $\mathrm{B}_{6}$ and vitamin $\mathrm{B}_{12}$ intake and depression in the SUN cohort study," Journal of Human Nutrition and Dietetics, vol. 22, no. 2, pp. 122-133, 2009.

[36] T. Tolmunen, J. Hintikka, A. Ruusunen et al., "Dietary folate and the risk of depression in finnish middle-aged men: a prospective follow-up study," Psychotherapy and Psychosomatics, vol. 73, no. 6, pp. 334-339, 2004.

[37] A. Sánchez-Villegas, P. Henríquez, M. Bes-Rastrollo, and J. Doreste, "Mediterranean diet and depression," Public Health Nutrition, vol. 9, pp. 1104-1109, 2006.

[38] M. H. Kamphuis, M. I. Geerlings, D. E. Grobbee, and D. Kromhout, "Dietary intake of $\mathrm{B}_{6-9-12}$ vitamins, serum homocysteine levels and their association with depressive symptoms: the Zutphen Elderly Study," European Journal of Clinical Nutrition, vol. 62, no. 8, pp. 939-945, 2008.

[39] T. T. Baldewicz, K. Goodkin, N. T. Blaney et al., "Cobalamin level is related to self-reported and clinically rated mood and to syndromal depression in bereaved HIV-1+ and HIV-1homosexual men," Journal of Psychosomatic Research, vol. 48, no. 2, pp. 177-185, 2000.

[40] K. Murakami, T. Mizoue, S. Sasaki et al., "Dietary intake of folate, other B vitamins, and $\omega-3$ polyunsaturated fatty acids in relation to depressive symptoms in Japanese adults," Nutrition, vol. 24, no. 2, pp. 140-147, 2008.
[41] H. Tiemeier, H. R. van Tuijl, A. Hofman, J. Meijer, A. J. Kiliaan, and M. M. B. Breteler, "Vitamin $\mathrm{B}_{12}$, folate, and homocysteine in depression: the Rotterdam study," The American Journal of Psychiatry, vol. 159, no. 12, pp. 2099-2101, 2002.

[42] T. Bottiglieri, M. Laundy, R. Crellin, B. K. Toone, M. W. P. Carney, and E. H. Reynolds, "Homocysteine, folate, methylation, and monoamine metabolism in depression," Journal of Neurology Neurosurgery and Psychiatry, vol. 69, no. 2, pp. 228$232,2000$.

[43] M. Folstein, T. Liu, I. Peter et al., "The homocysteine hypothesis of depression," The American Journal of Psychiatry, vol. 164, no. 6, pp. 861-867, 2007.

[44] T. Bottiglieri, "Homocysteine and folate metabolism in depression," Progress in Neuro-Psychopharmacology and Biological Psychiatry, vol. 29, no. 7, pp. 1103-1112, 2005.

[45] O. Stanger, W. Herrmann, K. Pietrzik et al., "DACH-LIGA homocystein (German, Austrian and Swiss homocysteine society): consensus paper on the rational clinical use of homocysteine, folic acid and B-vitamins in cardiovascular and thrombotic diseases: Guidelines and recommendations," Clinical Chemistry and Laboratory Medicine, vol. 41, no. 11, pp. 13921403, 2003.

[46] M. T. Abou-Saleh and A. Coppen, "Folic acid and the treatment of depression," Journal of Psychosomatic Research, vol. 61, no. 3, pp. 285-287, 2006.

[47] A. Coppen and C. Bolander-Gouaille, "Treatment of depression: time to consider folic acid and vitamin $\mathrm{B}_{12}$," Journal of Psychopharmacology, vol. 19, no. 1, pp. 59-65, 2005.

[48] A. L. Miller, "The methylation, neurotransmitter, and antioxidant connections between folate and depression," Alternative Medicine Review, vol. 13, no. 3, pp. 216-226, 2008.

[49] G. Zhao, E. S. Ford, C. Li, K. J. Greenlund, J. B. Croft, and L. S. Balluz, "Use of folic acid and vitamin supplementation among adults with depression and anxiety: a cross-sectional, population-based survey," Nutrition Journal, vol. 10, no. 1, article 102, 2011.

[50] A. L. Miller, "The methylation, neurotransmitter, and antioxidant connections between folate and depression," Alternative Medicine Review, vol. 13, no. 3, pp. 216-226, 2008.

[51] A. Coppen, C. Swade, S. A. Jones, R. A. Armstrong, J. A. Blair, and R. J. Leeming, "Depression and tetrahydrobiopterin: the folate connection," Journal of Affective Disorders, vol. 16, no. 2-3, pp. 103-107, 1989.

[52] A. Coppen and J. Bailey, "Enhancement of the antidepressant action of fluoxetine by folic acid: a randomised, placebo controlled trial," Journal of Affective Disorders, vol. 60, no. 2, pp. 121-130, 2000.

[53] J. M. Ruuskanen and I. Ruoppila, "Physical activity and psychological well-being among people aged 65 to 84 years," Age and Ageing, vol. 24, no. 4, pp. 292-296, 1995.

[54] L. L. Craft and F. M. Perna, "The benefits of exercise for the clinically depressed," Primary Care Companion to the Journal of Clinical Psychiatry, vol. 6, pp. 104-111, 2004.

[55] P. W. Ku, K. R. Fox, L. J. Chen, and P. Chou, "Physical activity and depressive symptoms in older adults: 11-year follow-up," The American Journal of Preventive Medicine, vol. 42, no. 4, pp. 355362, 2012.

[56] K. S. Kendler, L. M. Thornton, and C. A. Prescott, "Gender differences in the rates of exposure to stressful life events and sensitivity to their depressogenic effects," The American Journal of Psychiatry, vol. 158, no. 4, pp. 587-593, 2001. 
[57] O. J. Robinson, R. Cools, M. J. Crockett, and B. J. Sahakian, "Mood state moderates the role of serotonin in cognitive biases," Journal of Psychopharmacology, vol. 24, no. 4, pp. 573-583, 2010.

[58] J. H. Meyer, S. Krüger, A. A. Wilson et al., "Lower dopamine transporter binding potential in striatum during depression," NeuroReport, vol. 12, no. 18, pp. 4121-4125, 2001.

[59] A. J. Daley, H. Winter, C. Grimmett, M. McGuinness, R. McManus, and C. MacArthur, "Feasibility of an exercise intervention for women with postnatal depression: a pilot randomised controlled trial," The British Journal of General Practice, vol. 58, no. 548, pp. 178-183, 2008.

[60] M. Hamer, G. J. Molloy, C. de Oliveira, and P. Demakakos, "Leisure time physical activity, risk of depressive symptoms, and inflammatory mediators: the English Longitudinal Study of Ageing," Psychoneuroendocrinology, vol. 34, no. 7, pp. 1050-1055, 2009.

[61] J. M. Cyranowski, E. Frank, E. Young, and M. K. Shear, "Adolescent onset of the gender difference in lifetime rates of major depression: a theoretical model," Archives of General Psychiatry, vol. 57, no. 1, pp. 21-27, 2000.

[62] J. Veijola, P. Puukka, V. Lehtinen, J. Moring, T. Lindholm, and E. Väisänen, "Sex differences in the association between childhood experiences and adult depression," Psychological Medicine, vol. 28, no. 1, pp. 21-27, 1998.

[63] R. D. Goodwin and I. H. Gotlib, "Gender differences in depression: the role of personality factors," Psychiatry Research, vol. 126, no. 2, pp. 135-142, 2004.

[64] T. Yary, S. Aazami, and K. Soleimannejad, "Dietary intake of magnesium may modulate depression," Biological Trace Element Research, vol. 151, pp. 324-329, 2013. 

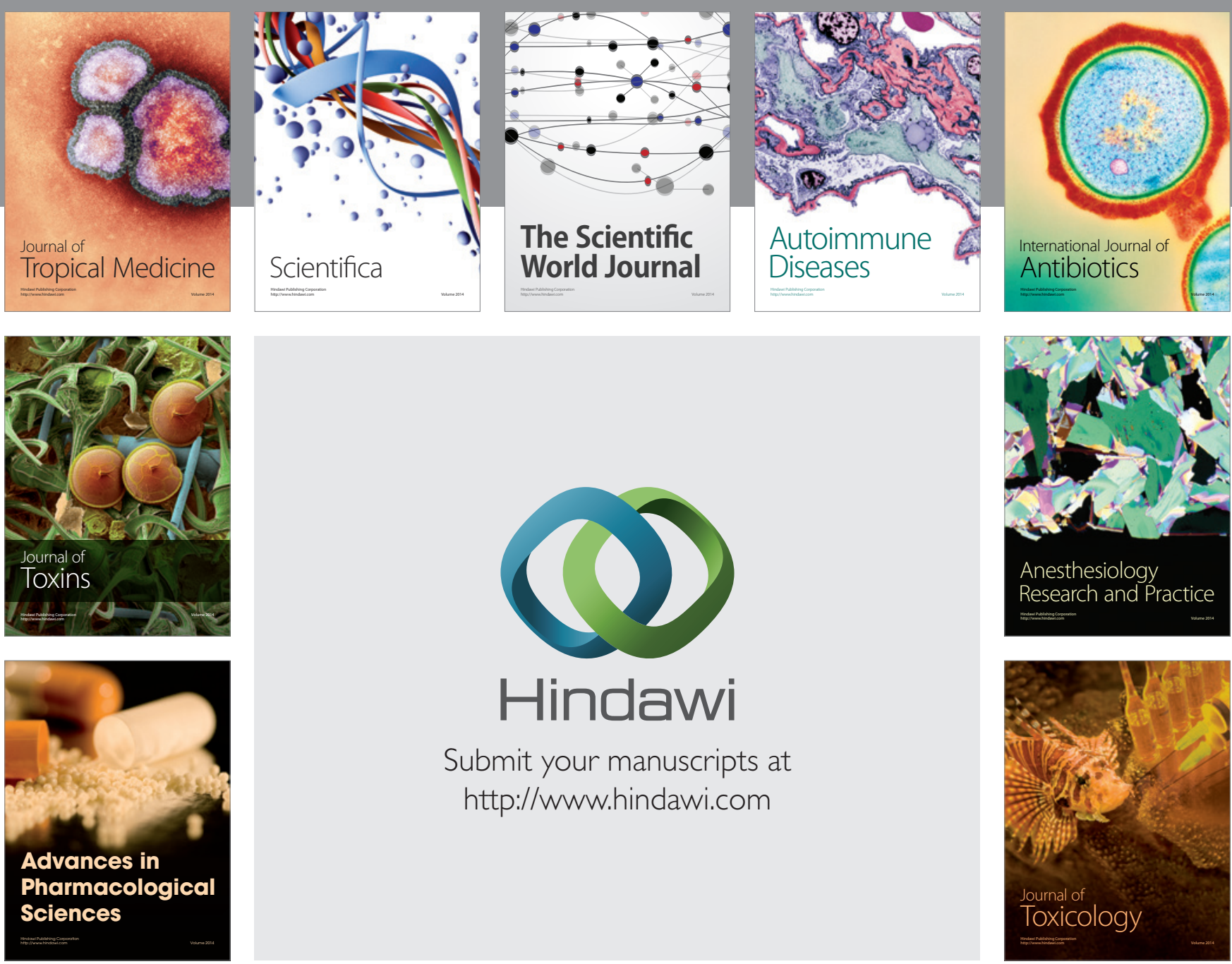

\section{Hindawi}

Submit your manuscripts at

http://www.hindawi.com
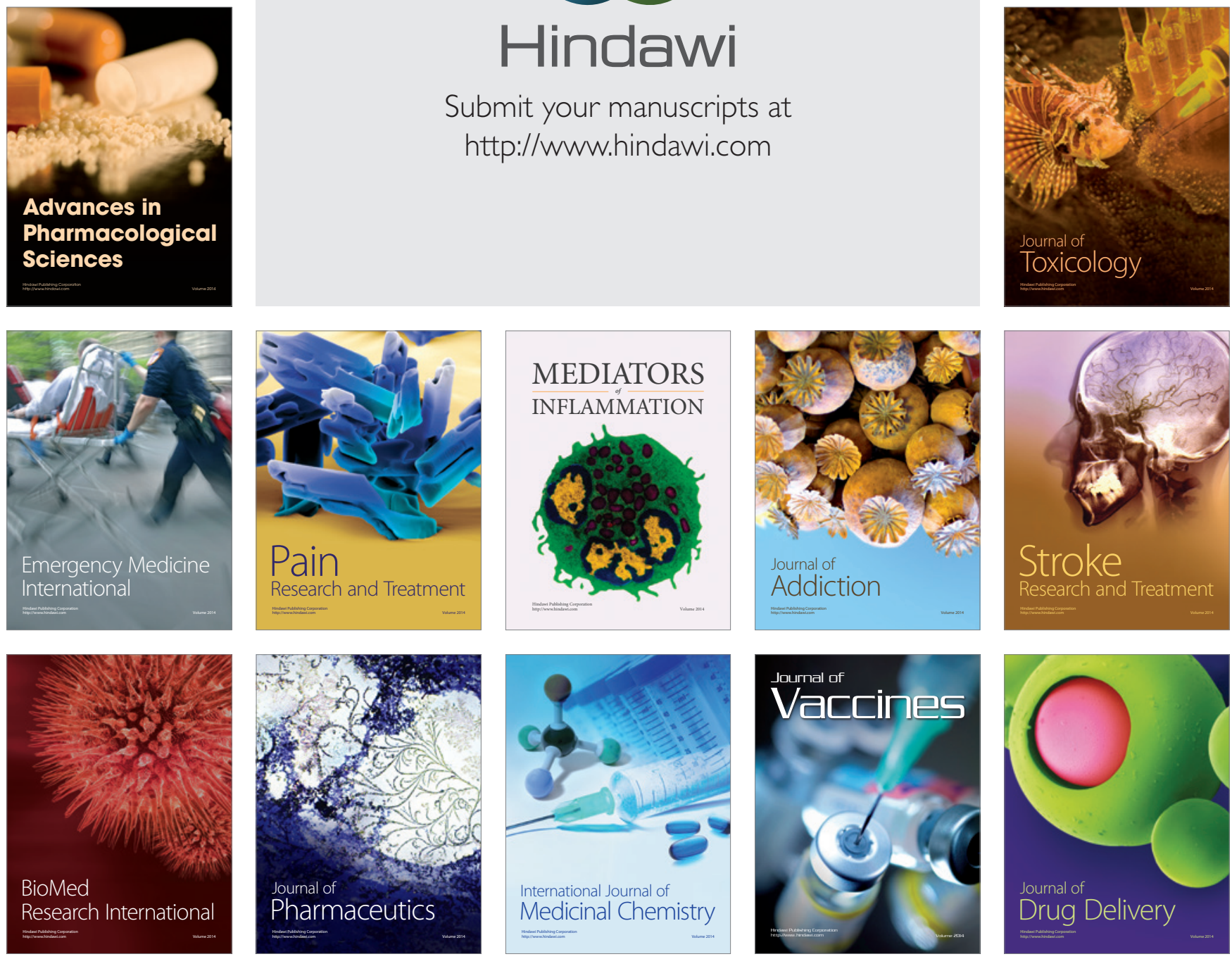